\title{
Holographic Observation of Magnetic Fine-Structures in New Magnetic Materials
}

\author{
T. Tanji*, S. Hasebe**, and T. Suzuki** \\ *CIRSE, Nagoya University, Chikusa, Nagoya 463-8603, Japan \\ **School of Engineering, Nagoya University, Chikusa, Nagoya 463-8603, Japan
}

New magnetic materials, metal multilayers $(\mathrm{Co} / \mathrm{Cu})$ and granular films $(\mathrm{Fe}-\mathrm{Zr})$, have been observed by electron holography. Giant magnetoresistance (GMR) is attributed to the spin-dependent scattering of conduction electrons, which arises from the magnetic coupling between each adjacent ferromagnetic layers through a nonmagnetic spacer layer (multilayers), or between neighboring ferromagnetic particles in nonmagnetic matrix (granular films). Direct observation of such a coupling, however, has hardly been reported so far.

$\mathrm{Co} / \mathrm{Cu}$ multilayers were deposited onto $\mathrm{Si}(111)$ wafers in a rf magnetron sputtering system. The thickness of a $\mathrm{Cu}$ layer was varied $1.5-3.5 \mathrm{~nm}$, while that of a Co layer was fixed to $4.0 \mathrm{~nm}$. The sample of $\mathrm{Co}(4.0 \mathrm{~nm}) / \mathrm{Cu}(2.0 \mathrm{~nm})$ shows the magnetic curve most like to indicate an antiferromagnetic ordering of Co layers (Fig.1). Therefore cross sections of $\mathrm{Si}[\mathrm{Co}(4.0 \mathrm{~nm}) / \mathrm{Cu}(2.0 \mathrm{~nm})]_{\mathrm{n}}, \mathrm{n}=4,5,6$ were observed by electron holography. Specimens were prepared by ordinary ion-milling. Fe-Zr granular films were prepared by annealing amorphous films of $\mathrm{Fe}_{80} \mathrm{Zr}_{20}$ which were deposited by dc magnetron sputtering at $-170^{\circ} \mathrm{C}$. An as-sputtered $\mathrm{Fe}-\mathrm{Zr}$ film shows scarcely clear ferromagnetism, and after annealing it shows a typical ferromagnetic curve (Fig.2). Particles precipitated were 10$30 \mathrm{~nm}$ in diameter. They were ascertained to consist mainly of Fe by a high spatial-resolution EDX. Electron holograms were recorded by Hitachi HF-2000 equipped with a low magnetic field objective lens and reconstructed on a PC using Gatan DigitalMicrograph scripts.

Figure 3 shows TEM image (a), reconstructed phase distribution (b), their profiles (c, d) and the magnetization direction (e) of $[\mathrm{Co}(4.0 \mathrm{~nm}) / \mathrm{Cu}(2.0 \mathrm{~nm})]_{4}$. Those of $[\mathrm{Co}(4.0 \mathrm{~nm}) / \mathrm{Cu}(2.0 \mathrm{~nm})]_{5}$ are shown in Fig.4. It is found that the magnetization of Co layers in $[\mathrm{Co}(4.0 \mathrm{~nm}) / \mathrm{Cu}(2.0 \mathrm{~nm})]_{4}$ have ferromagnetic ordering despite the antiferromagnetic form of the curve in Fig.1. While the magnetization in $[\mathrm{Co}(4.0 \mathrm{~nm}) / \mathrm{Cu}(2.0 \mathrm{~nm})]_{5}$ is separated to antiparallel two parts, the first two layers and the next three layers in which inside layers order ferromagnetically as shown in Fig.4. Such antiferromagnetic ordering has been found always in $[\mathrm{Co}(4.0 \mathrm{~nm}) / \mathrm{Cu}(2.0 \mathrm{~nm})]_{4}$ and sometimes in $[\mathrm{Co}(4.0 \mathrm{~nm}) / \mathrm{Cu}(2.0 \mathrm{~nm})]_{5}$ so far. The reason of this difference between the holographic observation and the magnetization curve is still under investigation.

Figure 5a shows phase distribution inside and outside of a Fe-Zr granular film, and the magnetic connection among the particles are drawn schematically in Fig.5b. A large particle at the center of Fig. $5 \mathrm{~b}$ seems to have a magnetic direction with a high angle against the film, so lines of magnetic force come into and out almost perpendicularly. 


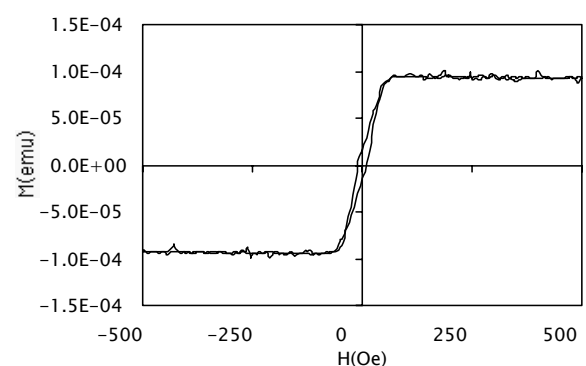

Fig.1: Hysteresis loop of a multilayered film $\mathrm{Si}[\mathrm{Co}(4.0 \mathrm{~nm}) / \mathrm{Cu}(2.0 \mathrm{~nm})]_{4}$.
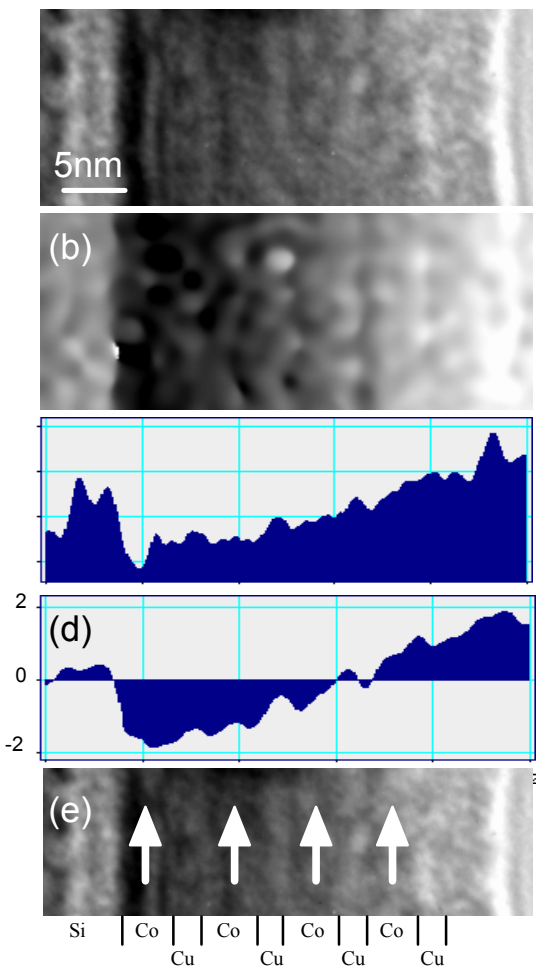

Fig.3: TEM image (a), reconstructed phase distribution (b), their profiles (c, d) and the indication of the magnetization direction (e) of $[\mathrm{Co}(4.0 \mathrm{~nm}) / \mathrm{Cu}(2.0 \mathrm{~nm})]_{4}$.

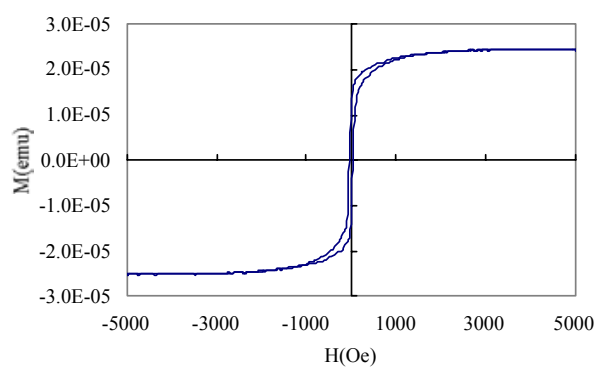

Fig.2: Hysteresis loop of an Fe-Zr granular film.
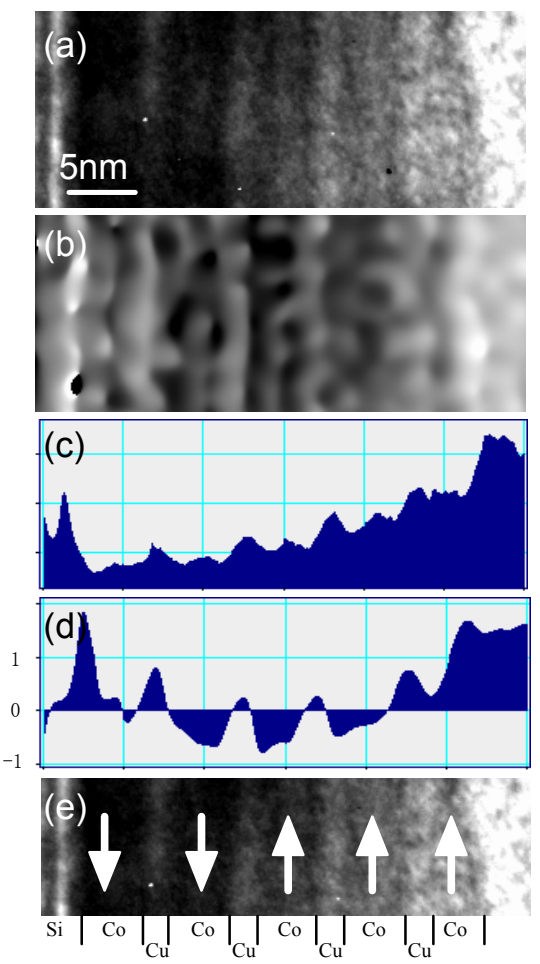

Fig.4: TEM image (a), reconstructed phase distribution (b), their profiles (c, d) and the indication of the magnetization direction (e) of $[\mathrm{Co}(4.0 \mathrm{~nm}) / \mathrm{Cu}(2.0 \mathrm{~nm})]_{5}$.
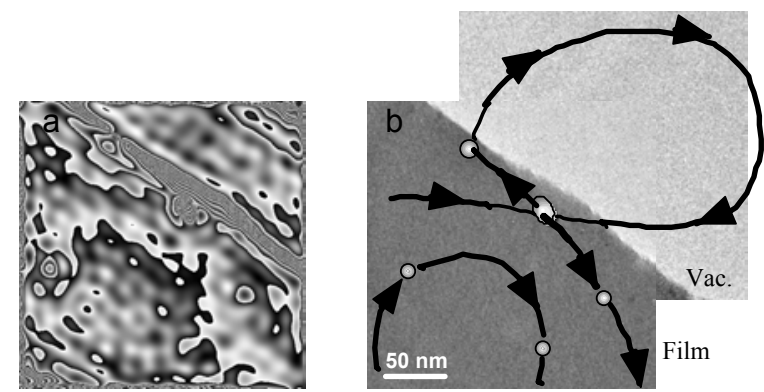

Fig.5: Phase distribution inside and outside of a Fe-Zr granular film (a), and the magnetic connection among the particles (b). 